\title{
Combined premedical-medical programmes: programme structure and student outcomes at four universities
}

\author{
LINDA GRANT $†$, LOUISE ARNOLD $\ddagger$, E. H. BLAUSTEINৎ, D. R. BROWNף, \\ SHEILA EDER †† \& L. MEISELAS††
}

$\dagger$ Department of Sociology, University of Georgia, Athens, Georgia, USA; $\ddagger$ Department of Medical Education Research, School of Medicine, University of Missouri, Kansas Ciy, Missouri, USA; \$College of Liberal Arts, Boston University, Boston, Massachusetts, USA; $\uparrow$ Centre for Research on Learning and Teaching, University of Michigan, Ann Arbor, Michigan, USA; $† \dagger$ Sophie Davis School of Biomedical Education, City College of New York, USA

Summary. Many American universities now support combined premedical-medical programmes which shorten and integrate the education of doctors. This paper reviews combined baccalaureate-MD programmes at four institutions: Boston University, the City College of New York, The University of Michigan-Ann Arbor, and the University of Missouri-Kansas City. In comparison to most US medical schools, the combined programmes have admitted and educated larger portions of women students. In addition, some have had large proportions of graduates choosing primary-care careers.

Key words: *Education, premedical; *Education, medical, undergraduate; *Curriculum; Sex ratio; Career choice; Primary health care/ man; Boston; New York City; Michigan; Missouri

\section{Introduction}

Many American universities have developed combined premedical-medical programmes which integrate undergraduate and medical school education (Blaustein \& Kayne 1976; Golmon et al.

Correspondence: Professor Linda Grant, Department of Sociology, University of Georgia, Baldwin Hall, Athens, Georgia I0602, USA.
1977; Wilkes College 1979; Pozen \& Sorenson r980). Shortening undergraduate-graduate medical education and avoiding duplication have been major goals. Some programmes have incorporated other goals, including a primarycare emphasis, preparation of students to care for the medically underserved, or integration of basic science and clinical education.

A comparative study of four integrated, combined-degree programmes in the United States assesses alternative designs of combined programmes, and outcomes for students (see Integrating and Accelerating Medical Education. Final Report to the Commonwealth Fund, 1983). Four programmes are compared: the 6-Year Programme at Boston University (BU); the Sophie Davis School of Biomedical Education at the City College of the City University of New York (CCNY); the Integrated Premedical-Medical Programme (Inteflex) at the University of Michigan at Ann Arbor (UMAA); and the combined programme at the University of Missouri-Kansas City (UMKC).

Each programme integrates premedical and medical education in different ways, and each exhibits distinctive student outcomes. The report is based on comparisons of classes which entered in 1972-1975, or 1973-1975 in the case of CCNY, whose first class entered in 1973. Since students matriculating in these years have now completed medical school, an examination of outcomes is possible. 


\section{Boston University and UMAA: combined programmes}

The programme at Boston University, established in 1961 , is the oldest. The BU programme accelerates the premedical phase for highly qualified students by consolidating professional premedical studies into two academic years. Third-year students join the regular medical student class for biomedical science classes and clinical rotations.

The UMAA Inteflex programme is also a combined programme developed within an already-existing medical school. The Inteflex Programme has a separate curriculum for 2 years, partial integration with the standard medical school programme in years 3 and 4, and full integration with standard students for clinical rotations. Its first-year students undertake a preceptorship with a primary-care physician in a small town.

\section{UMKC freestanding programme}

The UMKC programme represents a third approach. Before it opened in 1972 , there was no medical school in Kansas City, Missouri. UMKC's programme is thus a freestanding one. Rather than build a teaching hospital, the UMKC programme planners worked out affiliations with Kansas City hospitals for clinical teaching. UMKC integrates basic science, liberal arts and clinical work throughout the 6-year sequence. At entry, students join 10- to 14person docent teams, headed by a doctor and including social workers, nurses and allied health personnel. The programme has a strong primary-care emphasis and initiates clinical work the first year.

\section{CCNY: biomedical education}

The programme at CCNY has concentrated on students' premedical and biomedical sciences education. Students complete in 4 or 5 years a sequence equivalent to their undergraduate degree and the first 2 years of medical school. After 4 or 5 years at CCNY, students transfer to one of eight affiliated medical schools for clinical rotations. CCNY emphasizes primary care and treatment of underserved urban populations.

\section{Student outcomes}

The four programmes were compared with one another, and with standard programmes at $\mathrm{BU}$ and UMAA, on measures of student progress and performance, attitudes towards practice and social issues, and patterns of value development (see Integrating ... 1983). Students in all combined and standard programmes were similar. Attrition rates were higher in combined programmes than in all US medical schools (ranging from about $7 \%$ at $\mathrm{BU}$ to nearly $29 \%$ at CCNY). Combined programmes admit I 8- and I9-yearold students whose career goals may change, while standard programmes admit only graduates of 4-year premedical sequences.

Most attrition in combined programmes occurs in the premedical phase, and each programme has experienced less with successive classes. Data from UMAA show that the combined programme has lower attrition rates, especially for women, than the standard premedical pathway (Moore 1982). Staley \& Hoad (1977) report similar results for another programme. When premedical and medical school attrition are taken into account, the combined programmes have lower attrition rates than standard sequences.

Student outcomes result in part from student selection and in part from the effects of programmes on students. These influences cannot be fully separated for these four programmes. However, the combined programmes have made distinctive contributions to outcomes of medical education, especially in characteristics of students selected and career choices of graduates.

\section{Student characteristics}

The combined programmes have admitted larger proportions of women than most medical schools in comparable years and brought women to successful completion of their MD degrees more successfully. In 1972-75, women constituted $20.6 \%$ of US medical students (JAMA, 240:2822-2823, 1978). Comparable-year enrolments for combined degree programmes were $32 \cdot 2 \%$ at $\mathrm{BU}, 42 \cdot 3 \%$ at $\mathrm{CCNY}, 40 \%$ at UMAA and $37.8 \%$ at UMKC. CCNY data are for years I973-75. At BU proportions of women enrolled 
in combined and standard programmes were similar ( 32.2 and $32.9 \%$ respectively), while at UMAA there were more women in the combined than the standard programme ( 40 and $25 \%$ respectively).

CCNY and UMKC had higher proportions of black, Hispanic, and Oriental/Pacific Islander students than national averages in comparable years. Thirty-seven per cent of CCNY and $14 \%$ of UMKC students were minorities, compared to US averages of $8 \%$. Drop-out rates for women and minorities are slightly higher than for white males, but most admitted completed their degrees. Data available for the comparative study did not permit exploration of why combined programmes had greater success in attracting and retaining women. Studies at the University of Michigan reveal that women are more likely than men to abandon goals for careers as doctors during premedical education. Of premedical students who entered the university in $1972-1976$, $49.2 \%$ of the men, but only $28 \%$ of the women, entered medical school after completing undergraduate degrees (Moore 1982). There are male-female performance differences for premedical students, but these are not large enough to account for variations in medical school enrolment. Combined programmes omit the selection between premedical and medical education and avoid a point at which women might opt out readily from medical careers.

\section{Career choice patterns}

If family practice, internal medicine, obstetrics/ gynaecology, and paediatrics are considered primary care, the programmes show variations in graduates' career choice. First-year specialty choices of combined programme graduates were compared with all US medical graduates in comparable years. Choices represent US students' matches through the National Intern and Resident Matching Programme (NIRMP). Nationwide, $65.6 \%$ of graduates from 1972r975 classes chose a primary-care field. However, $80.7 \%$ of CCNY, $73.4 \%$ of UMKC, $54.2 \%$ of BU, and $49 \cdot 1 \%$ of UMAA students chose primary care. A substantial proportion (as high as $10 \%$ in the UMAA programme) chose flexible residencies, which can lead to primary-care careers. Thus, the two programmes with the strongest emphases on primary care were successful in encouraging large proportions of graduates to elect such careers.

Nationwide, women opt for primary care more than do males (Burkett \& Kunz I98I; Lorber 1984). At CCNY $90 \%$ of the women but $78 \%$ of the men chose primary care. At UMAA, $62 \%$ of the women but $41 \%$ of the men made such choices. At BU, gender differences were smaller, with $58 \%$ women and $52 \%$ men choosing primary care. At UMKC $73 \%$ of women and of men selected primary care.

\section{References}

Blaustein E.H. \& Kayne H.C. (1976) The accelerated medical programme and the liberal arts at Boston University. Journal of the American Medical Association 235, 2618-20.

Burkett G. \& Kunz D. (I98I) A comparison of the professional values and career orientations of male and female medical students: some unintended consequences of U.S. public policy. Health Policy and Education 4, 33-5.

Golmon M., Kessler R. \& Eckenhoff J. (1977) The Honors Programme in Medical Education at Northern University Medical School: A Critical Review. Evanston, Illinosis.

Lorber J. (1984) Women Physicians: Careers, Status, and Power. Tavistock, New York.

Moore W.E. (1982) Persistence and performance of men and women premedical and medical students. Paper presented at the annual meeting of the American Educational Research Association, New York City.

Pozen J.T. \& Sorenson J.R. (1980) Evaluation of the Boston University Liberal Arts-Medical Education Programme. Final Report to The National Fund for Medical Education.

Staley K.H. \& Hoad A.B. (r977) A longitudinal study of female premedical attrition. Journal of Medical Education 52, 849-54.

Wilkes College Office of Health Sciences (1979) A Review and Evaluation of the Wilkes-Hannemann Medical Education Programme as Contrasted with Other Abridged Medical Education Programmes in the United States. Wilkes-Barre, Pennsylvania.

Received 8 August 1984 ; editorial comments to authors I 6 January 1985 ; accepted for publication 22 July 1985 